\title{
Potencial do capim-quicuio em manter a produção e a qualidade do leite de vacas recebendo níveis decrescentes de suplementação
}

\author{
Paulo César de Faccio Carvalho ${ }^{1}$, Anneleen Katty Marie Yvonne Dewulf ${ }^{2}$, Anibal de Moraes ${ }^{3}$, \\ Carolina Bremm ${ }^{4}$, Júlio Kuhn da Trindade ${ }^{4}$, Claudete Reisdorfer Lang ${ }^{3}$
}

\footnotetext{
${ }^{1}$ Departamento de Plantas Forrageiras e Agrometeorologia, Universidade Federal do Rio Grande do Sul - UFRGS.

2 Programa de Pós-graduação em Agronomia, Universidade Federal do Paraná - UFPR.

${ }^{3}$ Departamento de Fitotecnia e Fitossanitarismo, Universidade Federal do Paraná - UFPR.

${ }^{4}$ Programa de Pós-graduação em Zootecnia, Universidade Federal do Rio Grande do Sul - UFRGS.
}

RESUMO - Com o objetivo de estudar alternativas de extensificação, avaliou-se o efeito da redução da oferta de suplemento (níveis de 100, 65, 45 e 20\% das exigências totais para produção) e de sua substituição por pastagens de capim-quicuio sobre a produção e composição de leite. O experimento foi realizado em delineamento de blocos completos casualizados, com três repetições, pelo método de pastejo com lotação contínua e taxa de lotação variável, tendo como meta a manutenção do pasto a $20 \mathrm{~cm}$ de altura. A produção de leite individual e por área apresentou resposta linear positiva com o nível de suplementação. Os componentes qualitativos do leite não foram alterados pela redução do uso de suplementos, contudo, as produções diárias de proteína bruta e gordura por vaca variaram com os níveis de suplementação. Vacas pastejando capim-quicuio não mantêm a produção de leite quando se reduz a oferta de suplemento.

Palavras-chave: bovinos, níveis de suplementação, produção de leite a pasto, qualidade do leite

\section{Kikuyo grass potential to maintain milk yield and quality from cows receiving decreasing levels of supplements}

\begin{abstract}
Aiming to study alternatives to extensification, it was evaluated the effect of supplement supply reduction (levels of 100, 65, 45 and $20 \%$ of the total requirements for production) and the possibility of its substitution by kikuyu grass on milk production and composition. The trial was performed using a completely randomized block design with three replicates, using the continuous and variable stocking rate grazing method aiming to keep the sward height at $20 \mathrm{~cm}$. Individual and per hectare milk production presented positive linear response with the supplementation level. The qualitative milk components were not modified by reducing the use of supplements, however, daily productions of crude protein and fat by the animal varied with the supplementation levels. Cows grazing kikuyu grass do not maintain their milk production when supplement offer is reduced.
\end{abstract}

Key Words: cattle, milk production from pasture, milk quality, supplementation levels

\section{Introdução}

Os debates recentes em torno das estratégias para o desenvolvimento de sistemas de produção sustentáveis têm apontado para a necessidade de se considerar, além da produtividade, enfatizado no passado, outros indicadores como a estabilidade e a sustentabilidade da produção (Carvalho etal., 2009). Em sistemas agrícolas, a sustentabilidade pode ser considerada como a manutenção da produção ao longo do tempo, sem degradação da base natural sobre a qual a produção é dependente (Nabinger \& Silva, 2000).

Comercialmente, o leite é um dos produtos cujo volume de produção é dependente de uma série de fatores ligados direta ou indiretamente ao sistema de produção (Mattos, 2000). O manejo da nutrição constitui-se na principal estratégia para alterar a composição do leite (Mattos \& Pedroso, 2005) a fim de atender distintas demandas de mercado. Segundo Fredeen (1996), a nutrição é responsável por 50\% da variação nos teores de proteína e gordura do leite, contudo, há pouco efeito para alterar os teores de lactose.

A utilização de pastagens de boa qualidade deve ser meta dos sistemas de produção de leite em pasto. Entretanto, vacas de alto mérito genético não conseguem obter na pastagem, mesmo que de boa qualidade, toda energia para alcançar o potencial produtivo. Neste contexto, a suplementação tem um papel importante na otimização da 
produção de leite à pasto (Branco et al., 2002). Segundo Muller \& Falles (1998), o potencial diário de produção de vacas pastejando exclusivamente gramíneas temperadas é de 25 a $30 \mathrm{~kg}$ de leite/vaca, contudo, em pastagens tropicais os resultados obtidos têm sido modestos (Assis et al. 2001). Hamilton et al. (1992) e Marais (2001) sugeriram que o potencial de produção diária de leite em pastagens de capim-quicuio (Pennisetum clandestinum Hochst. ex Chiov) fosse entre 12,0 e 14,7 kg/vaca, sendo conseqüência da limitante energia obtida pelo consumo da forragem. O insuficiente conteúdo de carboidratos solúveis e a lenta digestibilidade dos componentes estruturais leva a uma ineficiente utilização das elevadas concentrações de proteínas solúveis e degradáveis no rúmen (Hanna et al., 2004), freqüentemente encontradas nesta espécie.

Sob a hipótese de que vacas em pastagens bem manejadas podem manter elevada produção e qualidade do leite, objetivou-se avaliar o efeito do decréscimo da oferta de nutrientes via suplementos na dieta e sua complementação com nutrientes advindos de pastagens de capim-quicuio sobre o potencial de manter a produção e qualidade do leite.

\section{Material e Métodos}

O experimento foi realizado em área pertencente ao Colégio Instituto Cristão, localizado no município de Castro, Paraná, região fisiográfica do Primeiro Planalto Paranaense. As coordenadas geográficas aproximadas da área experimental são $24^{\circ} 47^{\prime} 28^{\prime \prime} \mathrm{S}, 50^{\circ} 00^{\prime} 43^{\prime \prime} \mathrm{W}$ e altitude de 934 m. O clima da região, segundo a classificação de Köppen, é temperado do tipo Cfb, (Iapar, 1994), com médias de temperatura dos meses mais frios inferiores a $18^{\circ} \mathrm{C}$ e médias dos meses mais quentes abaixo de $22^{\circ} \mathrm{C}$. A precipitação média anual varia entre 1.600 e $1.800 \mathrm{~mm}$. O solo da área experimental é uma associação de Cambissolo Háplico, Tb, de relevo ondulado, com Latossolo Bruno, de relevo suave ondulado, ambos distróficos típicos, com coloração variando entre vermelho escuro, vermelho-amarelo e amarelo, com uma textura argilosa e epieutróficos (Embrapa/ Fundação ABC, 2001).

O experimento foi conduzido em uma área de 8,4 ha formada com capim-quicuio (Pennisetum clandestinum Hochst. ex Chiov) com dois anos de estabelecimento antes do início do período experimental, o qual compreendeu os meses de outubro de 2006 a fevereiro de 2007. As adubações de cobertura foram realizadas nas seguintes datas: 27/7/2006, $100 \mathrm{~kg} /$ ha de adubo da fórmula 05:25:25(N:P:K); 8 e 14/9/2006, $54 \mathrm{~m}^{3}$ /ha de esterco líquido de suíno; 18/9/2006, 100 kg/ha de adubo da fórmula 21:00:21 (N:P:K); e 31/10/2006, 58 kg/ha de $\mathrm{N}$, na forma de ureia.
O delineamento experimental utilizado foi o de blocos completos casualizados, composto de quatro níveis de suplementação (100, 65, 45 ou 20\%), cada um com três repetições, totalizando 12 unidades experimentais (piquetes), com área entre 0,4 e 1,1 ha.

A suplementação fornecida em $100 \%$ foi calculada para atender a mantença de vacas produzindo 28 litros de leite/vaca/dia, considerando o perfil dos lotes de animais. Nos demais níveis de suplementação, os valores percentuais corresponderam à fração de nutrientes fornecida, por intermédio da suplementação, para a mesma produção de leite.

A dieta dos animais foi formulada com o auxílio do programa Spartan Ration Evaluator v. 2.02b (Michigan State University). O suplemento foi fornecido aos animais em dois momentos do dia, das $4 \mathrm{~h}$ às $5 \mathrm{~h} 45 \mathrm{~min}$ e das $13 \mathrm{~h} 30 \mathrm{~min}$ às $15 \mathrm{~h} 45 \mathrm{~min}$, sendo composto por $81 \%$ de silagem de milho, $12 \%$ de uma ração para vacas leiteiras, $6 \%$ de concentrado proteico e $1 \%$ de minerais (Tabela 1). A silagem de milho utilizada apresentou 22,2\% de matéria seca, $8,4 \%$ de proteína bruta, 56\% de fibra em detergente neutro e 61,6\% de nutrientes digestíveis totais. A ração utilizada no suplemento foi composta por milho, sal comum, farelo de soja, grão de soja integral, farelo de trigo, calcário calcítico, enxofre em pó, fosfato bicálcico, óxido de magnésio, premix vitamínico mineral e bicarbonato de sódio. Já o concentrado proteico foi composto por farelo de algodão, refinasil, sal comum, farelo de soja, farelo de trigo, calcário calcítico, enxofre em pó, fosfato bicálcico, premix vitamínico mineral e ureia. O suplemento resultante da combinação dos ingredientes apresentou composição média de $15 \%$ proteína bruta, $47 \%$ de fibra em detergente neutro, $63 \%$ de nutrientes digestíveis totais, $0,88 \%$ de cálcio e $0,51 \%$ de fósforo, com base na matéria seca.

Tabela 1 - Quantidade média (kg/vaca/dia) dos ingredientes utilizados no suplemento oferecido a vacas leiteiras em pastagem de capim-quicuio submetidas a níveis decrescentes de suplementação

\begin{tabular}{lcccc}
\hline Ingrediente & \multicolumn{4}{c}{ Nível de suplementação ${ }^{1}(\%)$} \\
\cline { 2 - 5 } & 100 & 65 & 45 & 20 \\
\hline Silagem de milho & 42,2 & 27,7 & 18,1 & 8,1 \\
SMBL $^{2}$ & 0,052 & 0,126 & 0,214 & 0,278 \\
BICOX $^{3}$ & 0,200 & 0,132 & 0,086 & 0,036 \\
B3B Especial $^{4}$ & 6,2 & 4,1 & 2,7 & 1,2 \\
B3C $^{5}$ & 3,16 & 2,06 & 1,354 & 0,596 \\
\hline
\end{tabular}

${ }^{1}$ Referente ao nível calculado para atender integralmente à demanda nutricional para a produção de leite, utilizando o software Spartan Ration Evaluator v.2.02b.

2 Suplemento mineral para bovinos de leite; ${ }^{3}$ Suplemento mineral tamponante para bovinos de leite; ${ }^{4}$ Ração para bovinos de leite com $18 \%$ de PB; ${ }^{5}$ Concentrado proteico para bovinos de leite com $31 \%$ de PB. 
O método de pastejo utilizado foi o de lotação contínua, com taxa de lotação variável (Mott \& Lucas, 1952). Os animais experimentais foram selecionados conforme equivalência no grupo racial, peso, paridade, estágio de lactação e produção de leite, constituindo-se um grupo de 48 vacas, sendo 36 da raça Holandesa e 12 da raça Jersey. Em cada unidade experimental, foram utilizados quatro animais “testers” com peso vivo inicial de $543,0 \pm 18,45 \mathrm{~kg}$, período de lactação de 4,2 \pm 0,37 mês e com número de parições de 3,5 $\pm 0,21$, além de um número variável de animais reguladores (vacas secas e novilhas). Essas eram utilizadas com o intuito de manter o pasto em condições equânimes de elevada oferta de matéria seca entre tratamentos. Os animais experimentais foram submetidos a um período de adaptação de 15 dias para adequação aos suplementos.

A condução das vacas para os procedimentos de ordenha e fornecimento de suplemento ocorria em dois momentos do dia, pela manhã das 4h às 7h30min e à tarde, das $13 \mathrm{~h} 30 \mathrm{~min}$ às $17 \mathrm{~h}$, períodos nos quais os animais não tinham acesso à pastagem. Esses procedimentos foram realizados simultaneamente para todos os níveis de suplementos.

A meta de altura dos pastos foi de $20 \mathrm{~cm}$ para todos os piquetes, sendo monitorada uma vez por semana utilizando um bastão graduado ("sward stick" - Barthram, 1985) em 50 pontos distribuídos aleatoriamente em cada piquete.

A taxa de acúmulo diário de matéria seca foi estimada a partir da técnica das gaiolas em triplo emparelhamento, como descrito por Moraes et al. (1990). Utilizaram-se três gaiolas de exclusão por piquete, com dimensões de $50 \times 50 \mathrm{~cm}$, que foram avaliadas em intervalos de 21 dias e realocadas em novos pontos representativos da condição média do pasto.

Para a avaliação da massa de forragem, foi utilizada a técnica de dupla amostragem baseada na altura do pasto (Frame, 1993). Nas amostras cortadas fora da gaiola de exclusão foram realizadas medidas de altura, sendo que os valores de matéria seca da amostra e altura geraram regressões que serviram para a estimativa da massa de forragem para cada piquete. A produção total de matéria seca foi calculada pelo somatório das produções de cada período, sendo que essas foram obtidas multiplicando-se a taxa de acúmulo diário pelo número de dias do período. A forragem cortada foi recolhida em sacos de papel, seca em estufa de ar forçado a $65^{\circ} \mathrm{C}$ por 72 horas e pesada em balança de precisão. Além disso, a partir das amostras de fora da gaiola, cortadas na avaliação da taxa de acúmulo de matéria seca, foram retiradas subamostras para fins de separação morfológica. Foram separados manualmente os componentes lâmina foliar, colmo+bainha e material senescente. Após a separação, esses componentes foram acondicionados em sacos de papel, isoladamente, e submetidos à secagem nos mesmos procedimentos acima referidos, e em seguida pesados, para a estimativa de suas proporções na massa de forragem.

Para determinação da composição química da forragem aparentemente selecionada pelos animais, foram realizadas amostragens a cada 15 dias, pela técnica de simulação de pastejo (Euclides et al., 1992). Posteriormente, as amostras de simulação de pastejo foram submetidas aos mesmos procedimentos de secagem das amostras cortadas de pasto. Após a secagem, as amostras foram moídas e encaminhadas ao laboratório para serem realizadas as análises dos teores de proteína bruta (PB) e fibra em detergente neutro (FDN), de acordo com as técnicas descritas pela AOAC (1984) e Goering \& Van Soest (1970), respectivamente, além do teor de nutrientes digestíveis totais (NDT) estimado por cálculo proposto por Barber et al. (1984).

A variação da massa corporal dos animais foi obtida através da determinação do peso vivo médio dos "testers" no decorrer do período experimental utilizando-se a medida do perímetro torácico com fita de pesagem (Heinrichs, 2007). A taxa de lotação foi calculada pelo somatório do peso vivo médio dos animais “testers” mais o peso médio dos animais reguladores multiplicado pelo número de dias nos quais esses permaneceram nas unidades experimentais, dividido pelo número de dias do período experimental.

A oferta de forragem correspondeu à razão entre a massa de forragem e a taxa de lotação, sendo expressa em $\mathrm{kg}$ de matéria seca de forragem $/ \mathrm{kg}$ de peso vivo (Sollenberger et al., 2005). Já as ofertas de proteína bruta e de nutrientes digestíveis totais da forragem foram calculadas através da multiplicação da oferta de forragem pelos percentuais dos referidos nutrientes no pasto.

As concentrações de proteína bruta e de nutrientes digestíveis totais por unidade de volume $\left(\mathrm{g} / \mathrm{m}^{3}\right)$ foram calculadas pela relação entre a quantidade dos referidos nutrientes e o volume, em m ${ }^{3}$ (área × altura). Para cálculo das concentrações dos nutrientes disponíveis no pasto, utilizou-se a multiplicação da massa de forragem pela altura do pasto e, para a determinação das concentrações de nutrientes do suplemento foi feita a multiplicação da área $\times$ altura do cocho que era coberta por suplemento.

Amostras de leite foram coletadas a cada 15 dias, e individualmente alocadas em recipiente próprio contendo conservante Bronopol ${ }^{\circledR}$ (2-bromo-2-nitropropano-1,3-diol). Realizou-se leitura de absorção infravermelha no equipamento Bentley $2000^{\circledR}$ para quantificar os teores de gordura e proteína. Além de quantificar os teores, também 
foi realizada a contagem de células somáticas totais por citometria de fluxo com o uso do equipamento Somacount $500^{\circledR}$.

A pesagem do leite foi realizada duas vezes por semana para a estimativa da produção durante o período experimental. Para fins de nivelamento da produção e para possibilitar a comparação entre os níveis de suplementação, a produção total foi convertida para o teor padrão de $4,0 \%$ de gordura, com a aplicação da fórmula: $\mathrm{L}=(0,4+0,15 \cdot x) \cdot \mathrm{L}_{1}$; em que $\mathrm{L}=$ produção de leite com $4,0 \%$ de gordura; $\mathrm{x}=$ teor de gordura do leite produzido; e $\mathrm{L}_{1}=$ produção (Andriguetto et al., 1983).

Os dados referentes às variáveis dos pastos e dos animais foram submetidos à análise de variância (teste F) em nível de 5\% de significância. Constatou-se, pela análise de variância, que a altura do pasto variou entre os tratamentos $(\mathrm{P}<0,05)$, variável esta utilizada como critério de manejo e que deveria apresentar resposta semelhante entre os tratamentos. Dessa forma, foi procedida análise de covariância com o objetivo de retirar o efeito da altura do pasto sobre todos os parâmetros avaliados. Entretanto, a covariável não apresentou efeito significativo $(\mathrm{P}>0,05)$ e optou-se por não utilizá-la no modelo estatístico de análise. Foram realizadas análises de regressão polinomial, conforme o modelo $\hat{Y}_{i j}=\beta_{0}+b_{1} A_{i}+b_{2} A_{i 2}+b_{3} A_{i 3}+\varepsilon_{i j}$, em que: $\hat{Y}_{\mathrm{ij}}=$ variável-dependente; $\beta_{0}=$ intercepto da regressão; $\mathrm{A}=$ variável-independente; $\mathrm{b}_{1}=$ coeficiente linear de regressão da variável Y em função da variável-independente; $\mathrm{b}_{2}=$ coeficiente quadrático de regressão da variável $\mathrm{Y}$ em função da variável independente; $b_{3}=$ coeficiente cúbico de regressão da variável Y em função da variável independente e $\varepsilon_{\mathrm{ij}}=$ erro aleatório residual. Os dados foram analisados por intermédio do programa estatístico SAS, versão 8.2 (2001).

\section{Resultados e Discussão}

A massa de forragem, a taxa de acúmulo diário de forragem, a produção total de matéria seca, a participação de material morto na massa forragem e os teores de proteína bruta, fibra em detergente neutro e nutrientes digestíveis totais não se ajustaram $(\mathrm{P} \geq 0,05)$ a nenhum modelo de regressão. A participação de lâmina foliar e colmos+bainhas na massa de forragem apresentaram modelo de regressão linear $(\mathrm{P}<0,05)$. Esses resultados atenderam aos preceitos da hipótese estudada, de que as características do pasto em oferta deveriam ser as mais semelhantes possíveis entre tratamentos (Tabela 2).

Detectou-se relação quadrática significativa $(\mathrm{P}<0,05)$ da altura dos pastos sobre os níveis descrescentes de suplementação, fruto do pouco estímulo que os animais tinham para pastejarem numa situação em que recebiam dieta total no cocho. Ainda que se tenha tentado controlar essa situação, por intermédio dos animais reguladores, os procedimentos não foram suficientes para que a altura do pasto do tratamento de maior nível de suplementação fosse semelhante à dos demais níveis.

A proporção dos componentes encontrados na composição morfológica do capim-quicuio indica uma baixa participação das lâminas foliares, ainda que a sua magnitude esteja dentro da faixa considerada normal, que é entre $30 \mathrm{e}$ 70\% (Herrero et al., 2000). A proporção de material senescente na massa de forragem foi elevada, o que fez com que a massa de lâminas propriamente estivesse entre 768 e $1.102 \mathrm{~kg}$. Como se pode observar, a diferença em massa de forragem foi de apenas $14 \%$, mas, se for considerada a massa de lâminas, essa diferença chega a 43\%.

Mais do que constatar essas diferenças, importante é interpretar se as condições criadas com o manejo do pasto eram suficientes ou não para se oportunizar máximo consumo

Tabela 2 - Características do pasto e da forragem aparentemente selecionada em pastos de capim-quicuio pastejado por vacas leiteiras sob suplementação

\begin{tabular}{|c|c|c|c|c|c|c|c|c|}
\hline \multirow[t]{2}{*}{ Item } & \multicolumn{4}{|c|}{ Nível de suplementação (\%) } & \multirow[t]{2}{*}{ Efeito $^{2}$} & \multirow[t]{2}{*}{$\mathrm{R}^{2}$} & \multirow[t]{2}{*}{ EPM } & \multirow[t]{2}{*}{ Valor de $\mathrm{P}$} \\
\hline & 100 & 65 & 45 & 20 & & & & \\
\hline Altura (cm) & 18,6 & 16,0 & 15,6 & 15,7 & Q & 0,93 & 0,5 & 0,0005 \\
\hline Massa de forragem (kg/ha de MS) & 2825 & 2865 & 2700 & 2510 & NS & 0,26 & 245 & 0,0889 \\
\hline Taxa de acúmulo (kg/ha de MS) & 53,8 & 57,7 & 52,5 & 54,6 & NS & 0,06 & 3,3 & 0,4251 \\
\hline Produção de forragem (kg/ha de MS) & 7545 & 7755 & 6925 & 7000 & NS & 0,15 & 669 & 0,2161 \\
\hline Lâminas foliares (\%) & 39,0 & 37,8 & 34,4 & 30,6 & $\mathrm{~L}$ & 0,54 & 3,1 & 0,0061 \\
\hline Comos e bainhas (\%) & 29,8 & 31,6 & 33,3 & 35,6 & $\mathrm{~L}$ & 0,64 & 1,7 & 0,0019 \\
\hline Material morto (\%) & 31,2 & 30,6 & 32,3 & 33,8 & NS & 0,14 & 2,6 & 0,2208 \\
\hline Proteína bruta (g/kg de MS) & 195 & 184 & 188 & 186 & NS & 0,06 & 1,2 & 0,4226 \\
\hline Fibra em detergente neutro (g/kg de MS) & 616 & 625 & 611 & 625 & NS & 0,02 & 1,4 & 0,6525 \\
\hline Nutrientes digestíveis totais (g/kg de MS) & 633 & 627 & 636 & 627 & NS & 0,02 & 1,0 & 0,6484 \\
\hline
\end{tabular}

${ }^{1}$ Referente ao nível calculado para atender integralmente à demanda nutricional para a produção de leite, utilizando o software Spartan Ration Evaluator v.2.02b. 2 NS = não significativo $(\mathrm{P} \geq 0,05) ; \mathrm{L}=$ efeito linear; $\mathrm{Q}=$ efeito quadrático; $\mathrm{C}=$ efeito cúbico. 
de pasto pelas vacas, na medida em que se retiraram frações dos nutrientes fornecidos pelos suplementos. Neste sentido, o modelo de utilização de pastos de capim-quicuio, apresentado por Herrero et al. (2000), indica que a baixa proporção de lâminas obtida neste experimento foi determinante na definição de condições limitantes ao consumo do pasto. Segundo o modelo, mais de $1.200 \mathrm{~kg}$ de massa de lâminas seriam necessários para maximizar o consumo de vacas em pastejo. Isto significa que, neste aspecto, as condições ideais para se testar a hipótese deste trabalho não foram atingidas.

As taxas de acúmulo foram inferiores às registradas por Fontaneli (2005), que, trabalhando com vacas leiteiras em pastejo, com lotação intermitente, encontrou taxas de acúmulo diárias da ordem de $107 \mathrm{~kg} / \mathrm{ha}$ de MS, com aplicação de 400 kg/ha de N, na região do Planalto do Estado do Rio Grande do Sul, Brasil.

Os teores de proteína bruta estão de acordo com os registrados na literatura para o capim-quicuio. Segundo Quinlan et al. (1975), os níveis de proteína bruta variam entre 15 e $18 \%$, podendo chegar a $20 \%$ em pastagens bem fertilizadas (Reeves et al., 1996b). Os teores de fibra em detergente neutro encontrados na dieta aparentemente selecionada pelos animais, independente do nível de suplementação oferecido, esteve dentro da faixa comumente encontrada em capim-quicuio (581-741 g/kg de MS) (Marais, 2001).

A taxa de lotação e a variação de massa corporal diminuíram linearmente $(\mathrm{P}<0,05)$ com o decréscimo no nível de suplementação (Figura 1). Quando em situações em que o consumo de nutrientes esteja assegurado pelo fornecimento abundante de suplemento, a capacidade de lotação pode ser elevada até valores que incrementam a produção animal por unidade de área, sem redução acentuada do desempenho individual (Rocha et al., 2003). Além disso, como resposta à suplementação para vacas leiteiras, quantidades adicionais de nutrientes seriam disponibilizadas para diminuir a mobilização de reservas corporais (Dillon et al., 2002) e, dessa forma, aumentar o desempenho dos animais.

A variação observada na massa corporal é um indicativo de que as vacas não mantiveram a ingestão de nutrientes equivalente à obtida no maior nível de suplementação no cocho. Para explicar esse fenômeno, a seguir será apresentada uma sequência de variáveis mensuradas e/ou calculadas no intuito de descrever a complexidade em que se deparam os animais quando são submetidos a um ambiente alimentar composto por alimentos de tão distintas características.
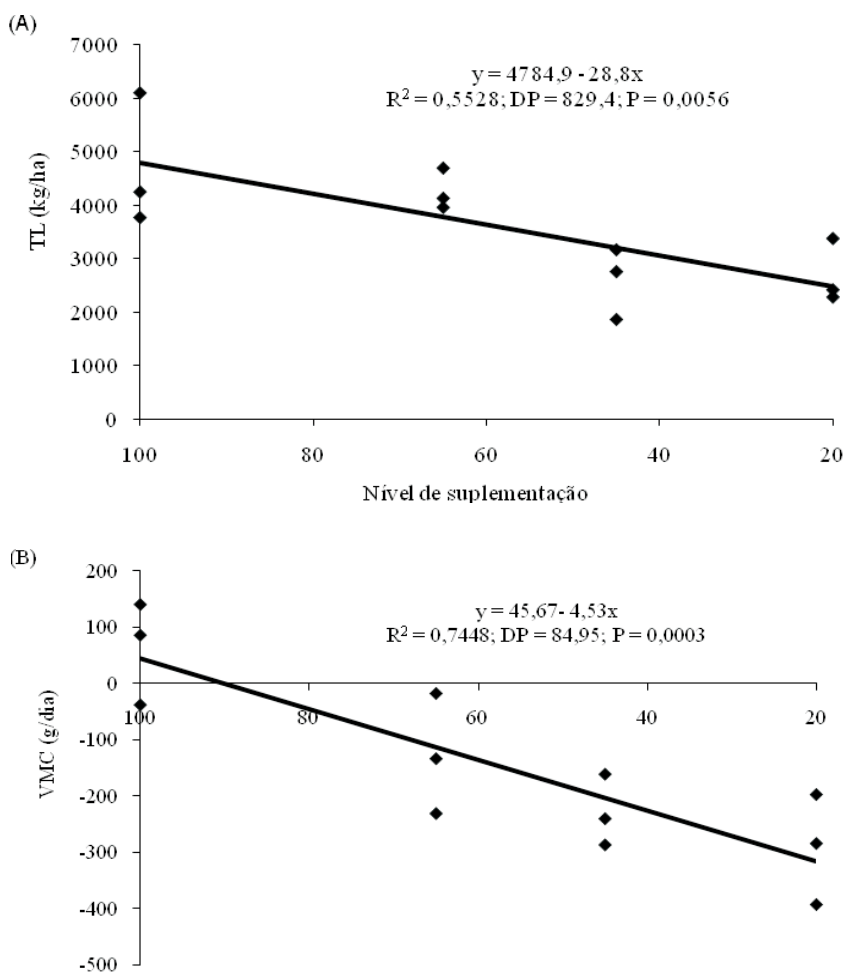

Nivel de suplementação

Figura 1 - Taxa de lotação (a) e variação de massa corporal (b) de vacas em pastagem de capim-quicuio sob suplementação.

Quando se consideram somente os nutrientes disponibilizados por intermédio do pasto (aqui exemplificados em termos de quantidade de forragem, proteína bruta e nutrientes digestíveis totais), a oferta de forragem, nutrientes digestíveis totais e proteína bruta aumentam linearmente com a diminuição nos níveis de suplementação (Figura 2), fato que está relacionado à redução linear da taxa de lotação, na medida em que menos suplemento era fornecido aos animais (Figura 1A).

Entretanto, não é necessário considerar somente aqueles nutrientes disponibilizados pelos suplementos, mas, sobretudo, considerá-los segundo uma mesma base de comparação. Nesse sentido, estimaram-se os valores nominais de proteína bruta e nutrientes digestíveis totais disponíveis por unidade de volume (Tabela 3), constatando-se resposta inversa à observada (Figura 2). Quando se observa a concentração de nutrientes por unidade de volume, maiores valores estiveram disponíveis no suplemento, assim como maiores valores nos maiores níveis de suplementação, quando comparados com os menores níveis. Dessa forma, elevadas concentrações de nutrientes totais, ou seja, provenientes do pasto e do suplemento, foram encontradas para as condições em que os animais receberam maiores quantidades de suplemento. 


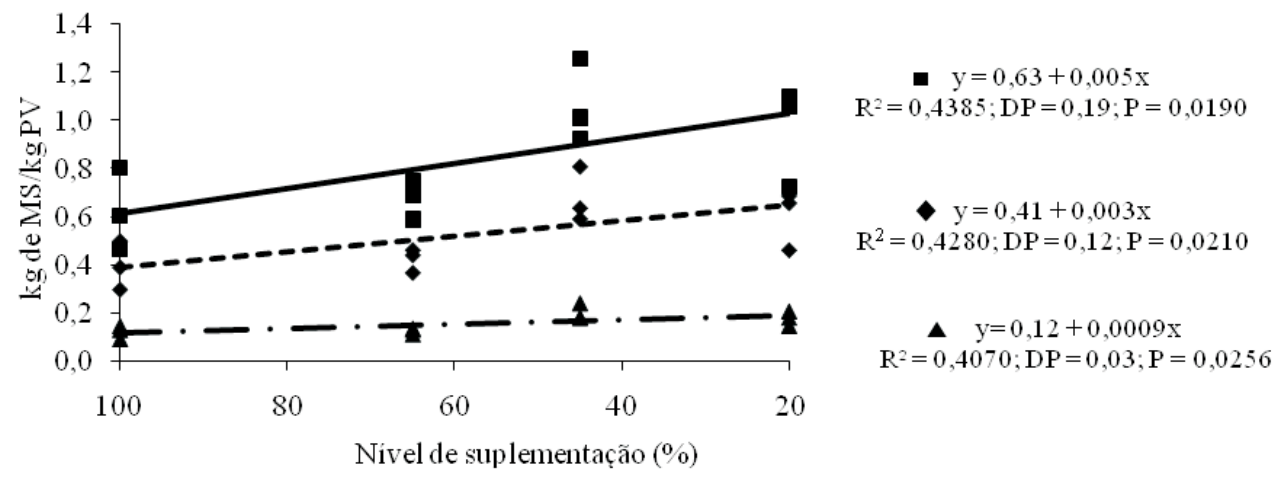

Figura 2 - Ofertas de forragem ( $\boldsymbol{\square})$, nutrientes digestíveis totais $(\bullet)$ e proteína bruta $(\boldsymbol{\Delta})$ de capim-quicuio com vacas submetidas a níveis decrescentes de suplementação.

Tabela 3 - Concentração de proteína bruta e de nutrientes digestíveis totais por unidade de volume disponíveis na pastagem de capimquicuio, no suplemento e na dieta total das vacas (pasto + suplemento)

\begin{tabular}{|c|c|c|c|c|}
\hline \multirow[t]{2}{*}{ Item } & \multicolumn{4}{|c|}{ Nível de suplementação ${ }^{1}$ (\%) } \\
\hline & 100 & 65 & 45 & 20 \\
\hline & \multicolumn{4}{|c|}{ Pasto } \\
\hline Proteína bruta ( $\mathrm{g} / \mathrm{m}^{3}$ de $\mathrm{MS}$ ) & 295 & 330 & 323 & 296 \\
\hline \multirow[t]{2}{*}{ Nutrientes digestíveis totais ( $\mathrm{g} / \mathrm{m}^{3}$ de $\mathrm{MS}$ ) } & 962 & 1121 & 1098 & 1000 \\
\hline & \multicolumn{4}{|c|}{ Suplemento } \\
\hline Proteína bruta ( $\mathrm{g} / \mathrm{m}^{3}$ de $\mathrm{MS}$ ) & 10119 & 8828 & 8653 & 4886 \\
\hline \multirow[t]{2}{*}{ Nutrientes digestíveis totais $\left(\mathrm{g} / \mathrm{m}^{3}\right.$ de $\mathrm{MS}$ ) } & 44904 & 37657 & 35791 & 19458 \\
\hline & \multicolumn{4}{|c|}{ Pasto + suplemento } \\
\hline Proteína bruta ( $\mathrm{g} / \mathrm{m}^{3}$ de $\mathrm{MS}$ ) & 10413 & 9158 & 8976 & 5183 \\
\hline Nutrientes digestíveis totais ( $\mathrm{g} / \mathrm{m}^{3}$ de $\mathrm{MS}$ ) & 45865 & 38778 & 36889 & 20458 \\
\hline
\end{tabular}

${ }^{1}$ Referente ao nível calculado para atender integralmente à demanda nutricional para a produção de leite, utilizando o software Spartan Ration Evaluator v.2.02b

Isto explica a variação negativa da massa corporal apresentada pelos animais, mas não somente isso. Com a redução da suplementação, na medida em que o nível de suplementação decresce de 100 para $20 \%$, os animais se vêem frente ao desafio de substituir um alimento altamente concentrado por outro altamente diluído. No nível de suplementação de $100 \%$, no qual supostamente ambas as fontes de alimentos estariam sendo oferecidas sem restrições, a diferença na concentração de nutrientes do suplemento em relação ao pasto é de 33 e 46 vezes, respectivamente para proteína bruta e nutrientes digestíveis totais por unidade de volume. Isto remete à afirmação de Carvalho et al. (2007), segundo os quais a velocidade de ingestão de nutrientes dita o consumo e o desempenho animal. Isto particularmente em sistemas em que exista elevada demanda nutricional, baixa concentração de nutrientes na matéria seca e tempo restrito para colheita de nutrientes. Este cenário é típico dos sistemas leiteiros baseados em pastagem. Vacas em pastejo são retiradas do pasto sempre que ordenhadas, ou seja, o tempo efetivo para pastejo pode ser diminuído, como no caso deste experimento, em até cinco horas, em virtude dos procedimentos envolvidos em cada ordenha. Enquanto alguns minutos de alimentação no cocho são suficientes para colher quase a totalidade dos nutrientes requeridos, várias horas de pastejo são incapazes para colher nutrientes com a mesma eficiência no pasto tal a diferença de concentração de nutrientes na MS do pasto em relação à do suplemento. Por isso, Carvalho et al. (2005) consideraram o pastejo como um processo tempo-dependente, e argumentaram que, em última análise, a diferença essencial entre sistemas de alimentação em cocho e em pasto seria o fator tempo, e a velocidade de ingestão o fator determinante do sucesso ou não de se ingerir a quantidade de nutrientes demandadas pelos requisitos produtivos (Palhano et al., 2007).

A produção de leite foi afetada pelos níveis de suplementação (Figura 3).

A produção de leite, tanto por animal quanto por área, decresceu linearmente com a redução dos níveis de suplementação $(\mathrm{P}<0,05)$. Como o cálculo da quantidade de suplemento foi elaborado em relação às exigências dos animais para produção potencial de leite, o fornecimento de 


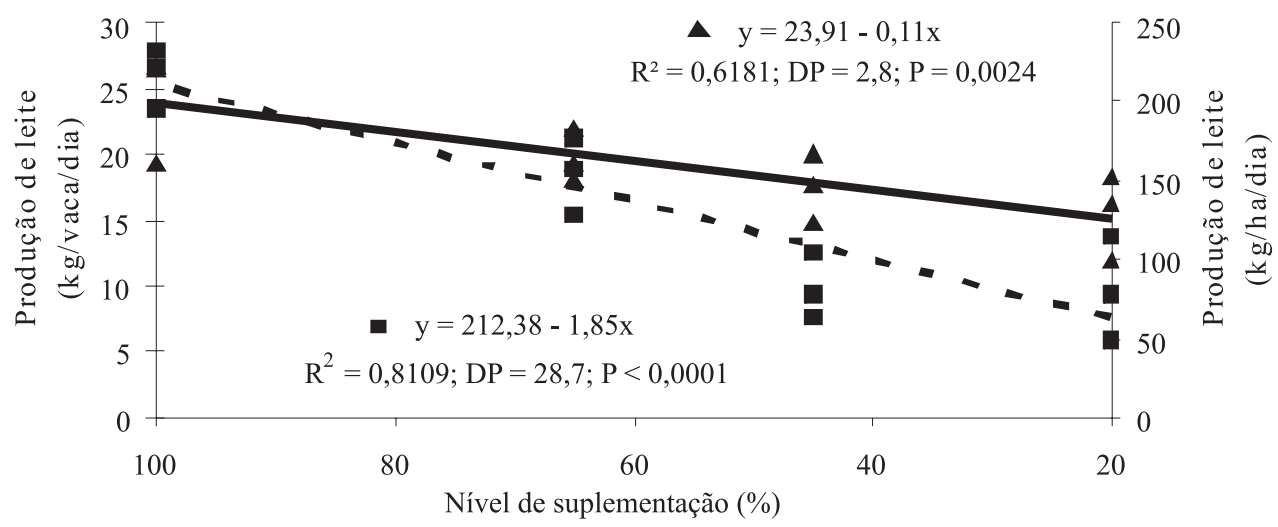

Figura 3 - Produção de leite por vaca ( $\boldsymbol{\Lambda}$, kg/vaca/dia) e por área ( $\mathbf{\square}, \mathrm{kg} / \mathrm{ha} /$ dia) em pastagem de capim-quicuio com suplementação.

100\% das exigências no cocho proporcionou máximas produções diárias, da ordem de 24,2 kg/vaca. Para atingirem essa produção nos níveis decrescentes de suplementação, as vacas necessitariam compensar a perda de nutrientes do suplemento pelos provenientes do pasto. Em outras palavras, incrementar o consumo de pasto. Entretanto, nesses tratamentos, a produção potencial não foi observada, o que deve estar relacionado com os elevados teores de fibra em detergente neutro e a baixa concentração de nutrientes no pasto, conforme discutido anteriormente. De fato, Marais (2001) afirma que o consumo de MS por vacas em capim-quicuio não excede $63 \mathrm{~g} / \mathrm{kg}$ de $\mathrm{PV}^{0,75}$, o que representaria $7,1 \mathrm{~kg}$ de $\mathrm{MS} / \mathrm{vaca} / \mathrm{dia}$ nas condições deste experimento. Segundo o autor, o consumo máximo de fibra em detergente neutro seria de 1,4\% do PV.

Em condições similares de alimentação (capim-quicuio + 5 kg de concentrado energético), Semmelmann (2007) observou produções diárias de leite de $18 \mathrm{~L} /$ vaca. No entanto, os valores de massa de forragem e de altura do pasto foram superiores, provavelmente significando melhores oportunidades de consumo de pasto.

As produções de leite por vaca, observadas no menor nível de suplementação no cocho, seriam aquelas que mais representariam o potencial do pasto em atender a produção de leite. Neste sentido, a magnitude da produção diária encontra respaldo na literatura, pois se reconhece o potencial do capim-quicuio como sendo para 13 a $16 \mathrm{~L} /$ vaca (Reeves et al., 1996).

A associação de elevados níveis de suplementação com alta taxa de lotação produziu valores de produção de leite por hectare que atingem $200 \mathrm{~kg} /$ dia. São valores bastante elevados e superiores aos observados por Semmelmann (2007), que registrou produções diárias de 72 kg/ha no Planalto Sul de Santa Catarina.

A contagem de células somáticas (CCS) não apresentou relação com os níveis de suplementação $(\mathrm{P}>0,05)$, sendo que o valor médio foi de 488,15 — 139,0 mil células/mL (Tabela 4), provavelmente devido ao fato dos animais receberem o mesmo manejo pré e pós-ordenha. Os resultados estão em conformidade com a composição mínima exigida pela Instrução Normativa 51 (Brasil, 2002).

Quanto aos teores de gordura do leite, esses não se ajustaram a nenhum modelo de regressão $(\mathrm{P}>0,05)$ quando os animais receberam níveis decrescentes de suplementação, com valores médios de $35,3 \pm 1,0 \mathrm{~g} / \mathrm{kg}$ de leite (Tabela 4). Os teores de proteína do leite também não apresentaram relação com os níveis de suplementação ( $P>0,05)$, com valor médio de 31,8 $\pm 1,2$ g/kg de leite, já que este é um componente do leite que apresenta muito pouca variação em decorrência de alterações da dieta. Semmelmann (2007) registrou, em vacas pastejando capimquicuio e recebendo $5 \mathrm{~kg}$ de concentrado energético à

Tabela 4 - Contagem de células somáticas, teores de gordura e proteína do leite de vacas em pastagem de capim-quicuio e submetidas a níveis decrescentes de suplementação

\begin{tabular}{|c|c|c|c|c|c|c|c|c|}
\hline \multirow[t]{2}{*}{ Item } & \multicolumn{4}{|c|}{ Níveis de suplementação $(\%)^{1}$} & \multirow[t]{2}{*}{ Efeito $^{2}$} & \multirow[t]{2}{*}{$\mathrm{R}^{2}$} & \multirow[t]{2}{*}{ EPM } & \multirow[t]{2}{*}{ Valor de $\mathrm{F}$} \\
\hline & 100 & 65 & 45 & 20 & & & & \\
\hline Contagem de células somáticas (mil células/mL) & 280 & 489 & 487 & 696 & NS & 0,29 & 139 & 0,0675 \\
\hline Teores de gordura no leite (g/kg de leite) & 36,4 & 33,7 & 34,8 & 36,4 & NS & 0,01 & 1,0 & 0,7474 \\
\hline Teores de proteína no leite ( $\mathrm{g} / \mathrm{kg}$ de leite) & 32,7 & 31,9 & 30,8 & 31,9 & NS & 0,08 & 1,2 & 0,3594 \\
\hline
\end{tabular}

${ }^{1}$ Referente ao nível calculado para atender integralmente à demanda nutricional para a produção de leite, utilizando o software Spartan Ration Evaluator v.2.02b.

2 NS - não-significativo ( $\mathrm{P} \geq 0,05)$; L - efeito linear; $\mathrm{Q}$ - efeito quadrático; C - efeito cúbico. 
base de milho, valores similares de 34,4 e 29,8 g/kg de leite para os teores de proteína e gordura, respectivamente. Já as produções diárias de proteína e de gordura do leite, expressas em g/vaca/dia, apresentaram resposta linear e negativa (Figura 4) com a diminuição dos níveis de suplementação $(\mathrm{P}<0,05)$.
Como pode ser observado, se não há relação do teor dos sólidos do leite com os níveis de suplementação, a resposta obtida (Figura 4) é reflexo direto da resposta da produção de leite. Os teores médios de gordura e proteína estão acima da composição mínima exigida pela Instrução Normativa 51 (Brasil, 2002).

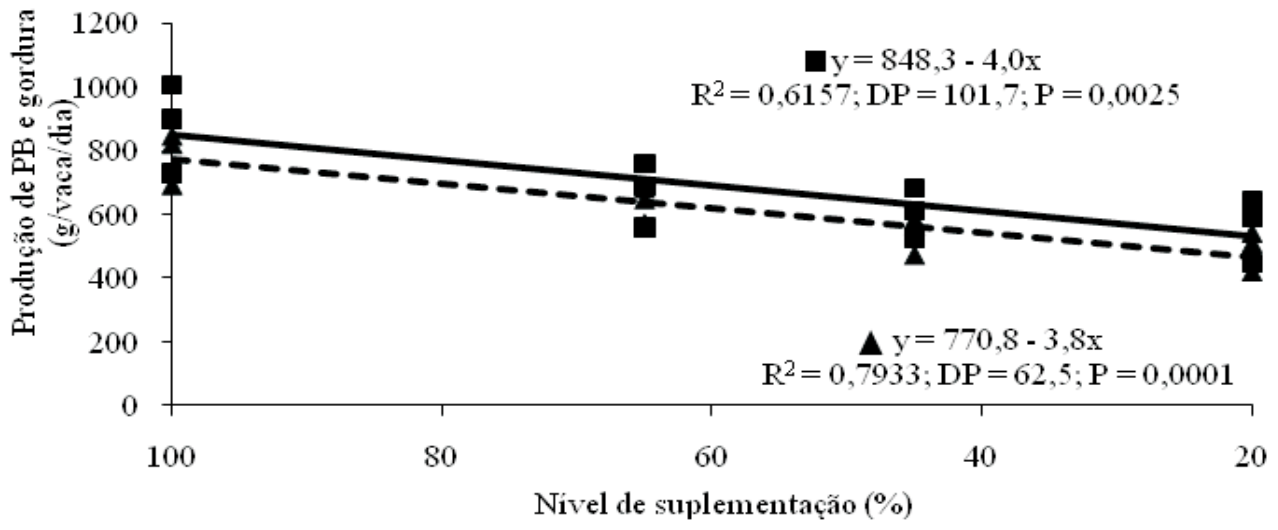

Figura 4 - Proteína ( $\boldsymbol{\Delta}, \mathrm{g} / \mathrm{vaca} /$ dia $)$ e gordura ( $\boldsymbol{\square}$,g/vaca/dia) do leite de vacas em pastagem de capim-quicuio e submetidas a níveis decrescentes de suplementação.

\section{Conclusões}

Vacas pastejando capim-quicuio não mantêm a produção de leite quando fornecidos baixos níveis de suplemento, uma vez que as características do pasto não são adequadas para máximo consumo. A elevada proporção de material senescente, associada à baixa proporção de lâminas foliares, limita o potencial do capim-quicuio em fornecer nutrientes para vacas, não obstante, os níveis de produção por unidade de área comprovam grande potencial de produção de sistemas à base de pastagem de capimquicuio quando há suplementação.

\section{Agradecimentos}

Os autores agradecem a colaboração do Instituto Cristão, da Cooperativa Castrolanda, da Fundação ABC e da Nutron e aos demais colaboradores.

\section{Referências}

ANDRIGUETTO, J.M.; PERLY, L.; MINARDI, I. et al. Nutrição animal: alimentação animal. vol. 2. São Paulo: Editora Nobel, 1983. 398p.

ASHES, J.R.; GULATI, S.K.; SCOTT, T.W. Potencial to alter milk fat through nutrition. Journal of Dairy Science. v.80, p.2204-2212, 1997.
ASSIS, A.G.; CAMPOS, O.F.; DIJKSTRA, J.A. et al. simulation model to evaluate supplementation of tropical forage diets for dairy cows. In: INTERNACIONAL GRASSLAND CONGRESS, 21., Proceedings... 2001. p.702-703.

ASSOCIATION OF OFFICIAL ANALYTICAL CHEMISTS AOAC. Official methods of analysis. 14.ed. Washington, D.C., 1984. 1141p.

BARBER, W.P.B.; ADAMSON, A.H.; ALTMAN, J.F.B. New methods of feed evaluation. In: HARESIGN, W.; COLE, D.J.A. (Eds.) Recent advances in animal nutrition. London: Butterworths, 1984. p.161-176.

BARTHRAM, G.T. Experimental techniques: the HFRO sward stick. In: ALCOCK, M.M. (Ed.) Biennial Report of the Hill Farming Research Organization. Midlothian: Hill Farming Research Organization, 1985. p.29-30

BRANCO, A.F.; CECATO, U.; OURO, G.F. Avaliação técnicoeconômica da suplementação de vacas leiteiras em pastagem. In: SIMPÓSIO SOBRE SUSTENTABILIDADE DA PECUÁRIA LEITEIRA NA REGIÃO SUL DO BRASIL, 2002, Maringá. Anais... Maringá: UEM/CCA/DZO-NUPEL, 2002. p.123-142.

BRASIL. Ministério da Agricultura, Pecuária e Abastecimento (MAPA). Departamento de Inspeção de Produto de Origem Animal. Instrução normativa $\mathrm{n}^{\circ}$ 51, de 18 de setembro de 2002. Aprova e oficializa o regulamento técnico de produção, identidade e qualidade, coleta e transporte de leite cru refrigerado. Diário Oficial da República Federativa do Brasil, Brasília, DF, 18 set. 2002. p.1-34.

CARVALHO, M.P. [1999] Gordura e proteína: como definir seus níveis na composição do leite. Disponível em: <http:// www.bichoonline.com.br/artigos/bb0010.htm> Acesso em: 16/11/2007.

CARVALHO, P.C.F.; GENRO, T.C.M.; GONÇALVES, E.N. et al. A estrutura do pasto como conceito de manejo: reflexos sobre o consumo e a produtividade. In: SIMPÓSIO DE VOLUMOSOS NA PRODUÇÃO DE RUMINANTES, 2., 2005, Jaboticabal. Anais... Jaboticabal: Unesp, 2005. p.107-124. 
CARVALHO, P.C.F.; KOZLOSKI, G.V.; RIBEIRO FILHO, H.M.N. et al. Avanços metodológicos na determinação do consumo por ruminantes em pastejo. Revista Brasileira de Zootecnia, v.36, p.151-170, 2007.

CARVALHO, P.C.F.; TRINDADE, J.K.; MEZZALIRA, J.C. et al. Do bocado ao pastoreio de precisão: Compreendendo a interface planta-animal para explorar a multifuncionalidade das pastagens. Revista Brasileira de Zootecnia, v.38, p.109-122, 2009.

DILLON, P.; CROSSE, S.; O’BRIEN, B. et al. The effect of forage type and level of concentrate supplementation on the performance of spring-calving dairy cows in early lactation. Grass and Forage Science, v.57, p.1-12, 2002.

EMBRAPA/FUNDAÇÃO ABC. Levantamento semidetalhado de solos - Município de Castro. Relatório Interno. Castro: EMBRAPA/SOLOS, EMBRAPA/FLORESTAS, FUNDAÇÃO ABC, 2001. 86p.

EUCLIDES, V.P.B.; MACEDO, M.C.M.; OLIVEIRA, M.P. Avaliação de diferentes métodos de amostragem sob pastejo. Revista Brasileira de Zootecnia, v.21, n.4, p.691-702, 1992.

FONTANELI, R.S. Produção de leite de vacas da raça Holandês em pastagens tropicais perenes no Planalto Médio do Rio Grande do Sul. 2005. 174f. Tese (Doutorado - Plantas Forrageiras) - Faculdade de Agronomia/Universidade Federal do Rio Grande do Sul, Porto Alegre.

FRAME, J. Herbage mass. In: HODGSON, J.; BAKER, R.D.; DAVIES, A. et al. (Eds.). Sward measurement handbook. Berkshire: British Grassland Society/Grassland Research Institute, 1993. p.39-69.

FREDEEN, A.H. Considerations in the nutritional modification of milk composition. Animal Feed Science and Technology, v.59, p.185-197, 1996.

GOERING, H.K.; VAN SOEST, P.J. Forage fiber analyses: apparatus, reagents, procedures, and some applications. Washington: USDA, 1970. 20p. (Agricultural Handbook, 379).

HAMILTON, B.A.; ASHES, J.R.; CARMICHAEL, A.E.W. Effect of formaldehyde-treated sunflower meal on the milk production of grazing dairy cows. Australian Journal of Agricultural Research, v.43, p.379-387, 1992.

HANNA, W.W.; CHAPARRO, C.; MATHEWS, B. et al. Perennial Pennisetums. In: MOSER, L.E.; BYRON, L.B.; SOLLENBERGER, L.E. (Eds.) Warm-season (C4) grasses. Madison: ASA/CSSA/ SSSA, 2004. p.503-535.

HEINRICHS, A.J.; ERB, H.N; ROGERS, G.W. et al. Variability in Holstein heifer heart-girth measurements and comparison of prediction equations for live weight. Preventive Veterinary Medicine, v.78, p.333-338, 2007.

HERRERO, M.; FAWCETT, R.H.; DENT, J.B. Modeling the growth and utilization of kikuyu grass (Pennisetum clandestinum) under grazing. 2. Model validation and analysis of management practices. Agricultural Systems, v.65, p.99-111, 2000.

INSTITUTO AGRONÔMICO DO PARANÁ. Cartas climáticas do estado do Paraná 1994. Londrina, 1994. 49p. (IAPAR Documento 18).

MARAIS, J.P. Factors affecting the nutritive value of kikuyu grass (Pennisetum clandestinum) - a review. Tropical Grasslands, v.35, p.65-84, 2001.

MATTOS, W.R.S.; PEDROSO, A.M. Influência da nutrição sobre a composição de sólidos totais de leite. In: SANTOS, F.A.P.; MOURA, J.C.; FARIA, V.P. (Eds.) Visão técnica e econômica da produção leiteira. SIMPÓSIO SOBRE BOVINO DE LEITE, 5., 2005, São Paulo. Anais... Piracicaba: FEALQ, 2005. p.103-129.
MATTOS, W.R.S. Medidas para o aumento da eficiência da produção leiteira. In: PEIXOTO, A.M.; MOURA, J.C.; FARIA, V.P. (Eds.) Bovinocultura leiteira: fundamentos da exploração racional. 3.ed. Piracicaba: FEALQ, 2000. p.383.

MORAES, A.; MOOJEN, E.L.; MARASCHIN, G.E. Comparação de métodos de estimativa de taxa de crescimento em uma pastagem submetida a diferentes pressões de pastejo. In: REUNIÃO ANUAL DA SOCIEDADE BRASILEIRA DE ZOOTECNIA, 27. 1990, Campinas. Anais... Piracicaba: FEALQ, 1990. p.332.

MOTT, G.O.; LUCAS, H.L. The design, conduct, and interpretation of grazing trials on cultivated and improved pastures. In: INTERNATIONAL GRASSLAND CONGRESS, 1952, Pennsylvania. Proceedings... Pennsylvania: State College Press, 1952. p.1380-1385.

MULLER, L.D.; FALLES, S.L. Supplementation of cool-season grass pastures for dairy cattle. In: CHERNEY, J.H.; CHERNEY, D.J.R. (Eds.). Grass for dairy cattle. Oxon: CAB Internacional, 1998. p.335.

NABINGER, C.; SILVA, J.L.S. Curso de atualização em produção animal a pasto. Porto Alegre: BRDE/UFRGS DPFA, 2000. 221p.

NATIONAL RESEARCH COUNCIL - NRC. Nutrient requirements of dairy cattle. 7. rev. ed. Washington, D.C.: National Academy Press, 2001. 381p.

PALHANO, A.L.; CARVALHO, P.C.F.; DITTRICH, J.R. et al. Características do processo de ingestão de forragem por novilhas holandesas em pastagens de capim-mombaça. Revista Brasileira de Zootecnia, v.36, n.4, p.1014-1021, 2007

QUINLAN, T.J.; SHAW, K.A., EDGLEY, W.H.R. Kikuyu grass. Queensland Agricultural Journal, v.101, p.737-739, 1975.

REEVES, M.; FULKERSON, W.J.; KELLAWAY, R.C. Forage quality of kikuyu (Pennisetum clandestinum): the effect of time of defoliation and nitrogen fertilizer application and in comparison with perennial ryegrass (Lolium perenne). Australian Journal of Agricultural Research, v.47, p.1349-1359, 1996.

ROCHA, M.G.; RESTLE, J.; PILAU, A. et al. Produção animal e retorno econômico da suplementação em pastagem de aveia preta e azevém. Ciência Rural, v.33, n.3, p.85-93, 2003.

SEMMELMANN, C.E.N. Suplementação nutricional em sistemas de produção de leite a pasto. 2007. 131f. Tese (Doutorado-Produção Animal) - Faculdade de Agronomia, Universidade Federal do Rio Grande do Sul, Porto Alegre.

SOLLENBERGER, L.E.; MOORE, J.E.; ALLEN, V.G. et al. Reporting forage allowance in grazing experiments. Crop Science, v.45, p.896-900. 2005.

STATISTICAL ANALYSIS SYSTEM - SAS. User's guide. Version 8.2 Cary: Statistical Analysis System Institute, 2001. 1686p.

SUTTON, J.D. Altering milk composition by feeding. Journal of Dairy Science, v.72, p.2801-2814, 1989.

WITTWER, F.M.M.V. Diagnóstico dos desequilíbrios metabólicos de energia em rebanhos bovinos. In: GONZÁLES, F.H.D.; BARCEllos, J.O.; OSPINA, H. et al. (Eds.) Perfil metabólico em ruminantes: seu uso em nutrição e doenças nutricionais. Porto Alegre, RS: Gráfica da Universidade Federal do Rio Grande do Sul, 2000. 108p.

WU, Z.; HUBER, J.T. Relationship between dietary fat supplementation and milk protein concentration in lactating cows: a review. Livestock Production Science, v.32, p.141-155, 1994. 